\title{
Peripubertal aromatase inhibition in male rats has adverse long-term effects on bone strength and growth and induces prostatic hyperplasia
}

\author{
Anurag Bajpai ${ }^{1,2}$, Peter J Simm ${ }^{1,2,3}$, Stephen J McPherson ${ }^{4}$, Vincenzo C Russo ${ }^{1,2,3}$, Walid J Azar ${ }^{1,2,3}$, \\ John D Wark ${ }^{5}$, Gail P Risbridger ${ }^{4}$ and George A Werther ${ }^{1,2,3}$ \\ ${ }^{1}$ Department of Endocrinology and Diabetes, Royal Children's Hospital, Parkville, Melbourne, Victoria 3052, Australia \\ ${ }^{2}$ Murdoch Childrens Research Institute, Centre for Hormone Research, Parkville, Melbourne, Victoria 3052, Australia \\ ${ }^{3}$ Department of Paediatrics, University of Melbourne, Melbourne, Victoria 3052, Australia \\ ${ }^{4}$ Prostate and Breast Cancer Research Group, Department of Anatomy and Developmental Biology, Monash University, Clayton, Victoria 3800, Australia \\ ${ }^{5}$ Department of Medicine and Bone and Mineral Service, The Royal Melbourne Hospital, University of Melbourne, Melbourne, Victoria 3052, Australia \\ (Correspondence should be addressed to P J Simm at Department of Endocrinology and Diabetes, Murdoch Childrens Research Institute, Centre of Hormone \\ Research, Royal Children's Hospital; Email: peter.simm@mcri.edu.au)
}

\begin{abstract}
Aromatase inhibitors have been increasingly used in boys with growth retardation to prolong the duration of growth and increase final height. Multiple important roles of oestrogen in males point to potential adverse effects of this strategy. Although the deleterious effects of aromatase deficiency in early childhood and adulthood are well documented, there is limited information about the potential long-term adverse effects of peripubertal aromatase inhibition. To address this issue, we evaluated short-term and long-term effects of peripubertal aromatase inhibition in an animal model. Peripubertal male Wistar rats were treated with aromatase inhibitor letrozole or placebo and followed until adulthood. Letrozole treatment caused sustained reduction in bone
\end{abstract}

strength and alteration in skeletal geometry, lowering of IGF1 levels, inhibition of growth resulting in significantly lower weight and length of treated animals and development of focal prostatic hyperplasia. Our observation of adverse long-term effects after peripubertal male rats were exposed to aromatase inhibitors highlights the need for further characterisation of long-term adverse effects of aromatase inhibitors in peripubertal boys before further widespread use is accepted. Furthermore, this suggests the need to develop more selective oestrogen inhibition strategies in order to inhibit oestrogen action on the growth plate, while beneficial effects in other tissues are preserved.

Journal of Endocrinology (2010) 207, 27-34

\section{Introduction}

The crucial role of oestrogen in mediating epiphyseal fusion in males was established by classical reports of men with defective oestrogen synthesis (aromatase deficiency; Morishima et al. 1995) and action (oestrogen receptor $\alpha$ deletion; Smith et al. 1994). These men in their twenties had tall stature and open epiphyses despite normal pubertal development and testosterone levels, indicating that oestrogen, and not testosterone, was responsible for epiphyseal fusion in men. This realisation prompted the development of a novel treatment for boys with short stature using aromatase inhibitors, which block oestrogen production in order to prolong the duration of growth and to increase final height. Beneficial effects of aromatase inhibitors on growth have been reported in boys with constitutional delay of puberty and growth, idiopathic short stature and $\mathrm{GH}$ deficiency (Wickman et al. 2001, Mauras et al. 2004, 2008, Hero et al. 2005, 2006b). The ease of administration, low cost and lack of overt toxicity of aromatase inhibitors make them a potential attractive strategy for treatment of boys with idiopathic short stature. This has led to a significant increase in the use of aromatase inhibitors in short boys, especially in North America and Europe (Shulman et al. 2008).

The use of aromatase inhibitors in young boys, however, remains 'off label', as these agents were primarily developed for the treatment of hormone-responsive breast cancer and preclinical studies were not performed in peripubertal males. Short-term follow-up (2-3 years) of boys treated with aromatase inhibitors has not shown significant adverse effects on areal bone density (Wickman et al. 2003), body composition (Hero et al. 2006a) or spermatogenesis (Mauras et al. 2005). However, these studies are limited by small sample size and short duration of follow-up. Importantly, many adverse effects of aromatase inhibition may not be manifested until adulthood. A fundamental assumption for the use of aromatase inhibitors in boys is that oestrogen deficiency has no deleterious consequences. However, this proposition is questioned by the important physiological role of oestrogen in males as illustrated by the development of osteoporosis 
(Bilezikian et al. 1998, Oz et al. 2000), adiposity phenotype (Morishima et al. 1995, Jones et al. 2000, Takeda et al. 2003) and impaired spermatogenesis (Carani et al. 1997, Robertson et al. 1999, Murata et al. 2002) in aromatase-deficient men and mice. These models, however, indicate the effects of longstanding oestrogen deficiency and are therefore not representative of selective peripubertal aromatase inhibition. Deleterious skeletal (Vanderschueren et al. 1997) and testicular (Turner et al. 2000) effects in adult Wistar rats treated with aromatase inhibitors suggest the potential of adverse effects of transient aromatase deficiency. However, the effects of transient aromatase inhibition in peripubertal males remain largely unexplored. We therefore developed an animal model to study these effects. In our study, peripubertal male Wistar rats were treated with letrozole, a highly selective, non-steroidal aromatase inhibitor. They were then followed up until early adulthood. The use of this model allowed us to study the long-term consequences of aromatase inhibition in peripubertal males.

\section{Materials and Methods}

The study was conducted at the large animal facility of the Royal Children's Hospital, Melbourne, Australia, in accordance with the Australian Code of Practice for the care and use of animals for scientific purposes, 2004. Ethical approval was obtained from the Animal Ethics Committee of the Royal Children's Hospital (AEC number 554).

\section{Animals}

Fifty 27-day-old male Wistar rats were obtained from Central Animal Services, Monash University, Clayton, Australia. After 3 days of acclimatisation, they were randomised to treatment $(n=25)$ and control $(n=25)$ groups. The animals were housed individually in similar environmental conditions (reverse day-night cycle with $12 \mathrm{~h}$ day and night, temperature $24^{\circ} \mathrm{C}$ ). They were fed oestrogen-free diet (AIN93M, Specialty Feeds, Perth, Western Australia, Australia) to avoid the confounding effect of environmental oestrogen exposure. No dietary- or water restrictions were imposed. The animals were inspected daily for well-being and weighed bi-weekly. Procedures were performed under anaesthesia induced by a combination of i.p. xylazine $(10 \mathrm{mg} / \mathrm{kg})$ and ketamine $(100 \mathrm{mg} / \mathrm{kg})$.

\section{Intervention}

The treatment group received letrozole orally (Femara, Novartis group, $1 \mathrm{mg} / \mathrm{kg}$ per day dissolved in 10\% gelatin; Nolan \& Levy 2006). The gelatin preparation was consumed avidly by the rats. They were treated from the peripubertal age of 30 days for 60 days until the age of 90 days. This is roughly equivalent of ages 10-18 years in human terms. The control animals received gelatin vehicle alone.
The animals were followed for an additional 90 days after completion of treatment until adulthood at the age of 180 days, which equates to around 30 human years of age (Fig. 1). Blood was obtained from the tail vein at the start of study (day 0), at the end of treatment (day 60) and at the end of study (day 150). Serum was separated and stored at $-70{ }^{\circ} \mathrm{C}$ until analysis. The animals were culled by injecting pentobarbital $(0.5 \mathrm{ml}$ of $340 \mathrm{mg} / \mathrm{ml}$; Virbac Animal Health, NSW, Australia).

\section{Blood assays}

Blood glucose was measured using a Medisense Optimum glucometer (Abbott Laboratories); insulin-like growth factor 1 (IGF1) was measured using a rat/mouse IGF1 ELISA (Immunodiagnostic Systems Ltd (IDS), Fountain Hill, AZ, USA) with intra- and inter-assay coefficients of variation (CV) of $4 \cdot 3-8 \cdot 8$ and $6 \cdot 3-8 \cdot 8 \%$ respectively. A rat/mouse GH kit (Linco Diagnostics, St Charles, MO, USA) was used for measurement of $\mathrm{GH}$ (intra-assay $\mathrm{CV} 1 \cdot 7-4 \cdot 3 \%$; inter-assay CV $3 \cdot 2-4 \cdot 9 \%$ ) on a single sample. Bone turnover was assessed with the bone formation marker serum osteocalcin (rat osteocalcin EIA kit, Biomedical Technology Inc., Stoughton, MA, USA; intra-assay variation 4\%; inter-assay variation $7 \%$ ) and the bone resorption marker C-terminal telopeptide $\alpha 1$ chain of type I collagen (RATLAPS from IDS; intra-assay variation $<10 \%$, inter-assay variation $<15 \%$ ). $\mathrm{LH}$ and $\mathrm{FSH}$ were measured by RIA with the following iodinated preparations (iodinated using Iodogen reagent (Sigma) and anti-sera: recombinant (r) FSH 1-8 and anti-rFSH-S-11, and rLH-1-9 and anti-rLH-S-10 (NIDDK, Bethesda, MD, USA)). The secondary antibody used in both RIAs was goat anti-rabbit IgG (GAR no. 12; Monash Institute of Reproduction and Development, Monash University, Melbourne, Australia), and the assay buffer was $0 \cdot 01 \mathrm{M}$ PBS containing $0 \cdot 5 \%$ BSA (Sigma). All samples were measured in a single assay as described previously (O’Donnell et al. 1994). Serum levels of testosterone were determined using the DSL-4000-coated tube RIA as per the manufacturer's instructions (Diagnostic System Laboratories Inc., Webster, TX, USA). Insulin (intra-assay CV 1·15-3.65\%; inter-assay CV 6.71-9.23\%) levels were measured using kits from Linco Diagnostics.
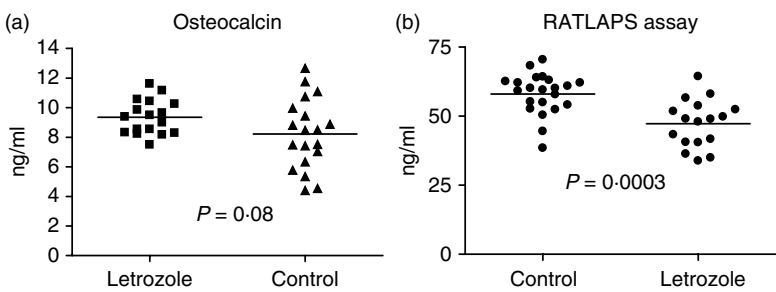

Figure 1 Results from bone turnover markers. (a) No significant difference in bone formation, as assessed by measuring serum osteocalcin levels, was observed between treated and non-treated animals. (b) Bone resorption, as assessed by RATLAPS assay, was significantly reduced in letrozole-treated animals as compared to controls. 


\section{Dual energy $X$ ray absorptiometry}

Dual energy X ray absorptiometry (DXA) was performed at the end of treatment (day 60) and at the end of study (day 150) using a QDR 4500A densitometer (Hologic Inc., Bedford, MA, USA) with dedicated small animal software (V9 L1 Rev A for acquisition and rat whole body V8.26a for analysis). Total mass, lean mass, fat mass and percentage of body fat were determined by whole body DXA. Tibial and crown-rump lengths were measured using the DXA image at both time points.

\section{Peripheral quantitative computed tomography}

Peripheral quantitative computed tomography (PQCT) of the tibia was performed at the end of treatment (day 60) and at the end of study (day 150) using an XCT Research SA+ densitometer (Stratec Medizintechnik GmbH, Pforzheim, Germany) by a single-blinded observer. Two CT slices were obtained at distances of 4 and 30\% tibial length from the end of the left tibia to assess trabecular and cortical bone respectively. Contour mode 1 and peel mode 20 were used for analysis. A voxel size of $0 \cdot 1 \mathrm{~mm}$ was selected. Crosssectional bone area and volumetric bone density were calculated at both sites. Cortical thickness, periosteal circumference, endosteal circumference and stress-strain index were measured at the $30 \%$ site.

\section{Prostate}

The weight of individual lobes of the prostate was measured at the time of culling. Prostate was fixed in modified Bouin's solution, embedded in paraffin and cut into $5 \mu \mathrm{m}$ sections as described earlier. Tissue sections were stained with haematoxylin and eosin to study morphological changes or subjected to immunohistological examination using antibodies to proliferating cell nuclear antigen (PCNA; PC10; Dako Corp., Carpinteria, CA, USA) or Apoptag.
Analyses of PCNA and apoptotic marker immunolocalisation were conducted using CAST software (version 2.1.4; Olympus Corp., Albertslund, Denmark) as described earlier (McPherson et al. 2001).

\section{Testes}

The weight of both testes was measured at the end of study. The testis was fixed in Bouin's solution and transferred into $70 \%$ ethanol. Testicular histology evaluation included assessment for disruption of spermatogenesis, and immunohistochemical analysis of cellular proliferation and apoptosis.

\section{Statistical analysis}

The study was powered to detect a difference of 1 SDS in stress-strain index with a power of $80 \%$ and a level of significance of $0 \cdot 05$. Seventeen animals were required in each group. We enrolled 25 animals in each group to allow for attrition. Data were expressed as mean \pm s.D. SPSS version 10 (IL, USA) was used for statistical analysis. Quantitative parameters in the two groups were analysed using a two-tailed unpaired Student's $t$-test. A $P$ value $<0 \cdot 05$ was considered significant.

\section{Results}

Of the 25 animals in each group, 5 (3 in the treatment group and 2 controls) died due to anaesthetic complications. Data for 22 animals in the treatment group and 23 animals in the control group are presented.

\section{Skeleton}

PQCT showed lower cross-sectional trabecular and cortical bone area in the treated animals (Table 1). This was associated with reduced periosteal and endosteal circumference and cortical thickness at the $30 \%$ tibial (cortical) site.

Table 1 Peripheral quantitative computed tomography skeletal parameters observed in the study

\begin{tabular}{|c|c|c|c|c|c|c|}
\hline & \multicolumn{2}{|c|}{ End of treatment (day 60) } & \multirow[b]{2}{*}{$\boldsymbol{P}$} & \multicolumn{2}{|c|}{ End of study (day 150) } & \multirow[b]{2}{*}{$\boldsymbol{P}$} \\
\hline & Treatment & Control & & Treatment & Control & \\
\hline \multicolumn{7}{|l|}{ Parameter } \\
\hline Trabecular cross sectional area $\left(\mathrm{mm}^{2}\right)$ & $15 \cdot 5 \pm 1 \cdot 2$ & $18 \cdot 7 \pm 0 \cdot 9$ & $<0 \cdot 0001$ & $18 \cdot 0 \pm 1 \cdot 1$ & $20 \cdot 5 \pm 1 \cdot 6$ & $<0 \cdot 0001$ \\
\hline Trabecular density $\left(\mathrm{mg} / \mathrm{mm}^{3}\right)$ & $403 \cdot 3 \pm 28 \cdot 1$ & $401 \cdot 7 \pm 37 \cdot 6$ & $0 \cdot 87$ & $448 \cdot 2 \pm 39 \cdot 1$ & $435 \cdot 7 \pm 51 \cdot 9$ & $0 \cdot 37$ \\
\hline Cortical cross sectional area $\left(\mathrm{mm}^{2}\right)$ & $4 \cdot 6 \pm 0 \cdot 3$ & $5 \cdot 8 \pm 0 \cdot 4$ & $<0 \cdot 0001$ & $6 \cdot 1 \pm 0 \cdot 4$ & $7 \cdot 4 \pm 0.6$ & $<0 \cdot 0001$ \\
\hline Cortical density $\left(\mathrm{mg} / \mathrm{mm}^{3}\right)$ & $1207 \cdot 0 \pm 16 \cdot 7$ & $1210 \cdot 7 \pm 28 \cdot 4$ & $0 \cdot 62$ & $1275 \cdot 9 \pm 13 \cdot 1$ & $1279 \cdot 3 \pm 12 \cdot 7$ & $0 \cdot 38$ \\
\hline Cortical thickness (mm) & $0 \cdot 50 \pm 0.03$ & $0 \cdot 60 \pm 0 \cdot 03$ & $<0 \cdot 0001$ & $0.70 \pm 0.02$ & $0.73 \pm 0.03$ & $0 \cdot 002$ \\
\hline Cortical thickness/TL (mm/cm) & $0 \cdot 138 \pm 0 \cdot 011$ & $0 \cdot 148 \pm 0 \cdot 011$ & $0 \cdot 005$ & $0 \cdot 166 \pm 0 \cdot 012$ & $0 \cdot 157 \pm 0 \cdot 009$ & $0 \cdot 01$ \\
\hline Periosteal circumference (mm) & $10 \cdot 6 \pm 0 \cdot 4$ & $11 \cdot 8 \pm 0 \cdot 7$ & $<0 \cdot 0001$ & $11 \cdot 0 \pm 0 \cdot 5$ & $12 \cdot 4 \pm 0 \cdot 7$ & $<0 \cdot 0001$ \\
\hline Periosteal circumference/TL (mm/cm) & $2 \cdot 84 \pm 0 \cdot 28$ & $2 \cdot 99 \pm 0 \cdot 21$ & $0 \cdot 05$ & $2 \cdot 62 \pm 0 \cdot 13$ & $2 \cdot 68 \pm 0 \cdot 18$ & $0 \cdot 23$ \\
\hline Endosteal circumference $(\mathrm{mm})$ & $7 \cdot 4 \pm 0 \cdot 5$ & $8 \cdot 1 \pm 0 \cdot 8$ & $0 \cdot 001$ & $6 \cdot 7 \pm 0.6$ & $7 \cdot 8 \pm 0 \cdot 6$ & $<0.0001$ \\
\hline Endosteal circumference/TL $(\mathrm{mm} / \mathrm{cm})$ & $1 \cdot 97 \pm 0 \cdot 26$ & $2 \cdot 06 \pm 0 \cdot 20$ & $0 \cdot 23$ & $1.58 \pm 0.09$ & $1 \cdot 69 \pm 0 \cdot 15$ & 0.006 \\
\hline Stress-strain index $\left(\mathrm{mm}^{4}\right)$ & $4 \cdot 0 \pm 0 \cdot 5$ & $5 \cdot 6 \pm 0 \cdot 5$ & $<0 \cdot 0001$ & $5 \cdot 1 \pm 0 \cdot 5$ & $7 \cdot 0 \pm 1 \cdot 1$ & $<0.0001$ \\
\hline
\end{tabular}

$\mathrm{TL}$, tibial length. 
No difference was seen between the cortical and trabecular volumetric bone mineral density in the two groups. Treated animals had reduced linear skeletal growth as reflected by lower tibial length at the end of treatment $(37 \cdot 2 \pm 2 \cdot 6$ vs $40.8 \pm 1.7 \mathrm{~mm}, P<0 \cdot 0001)$ and at the end of study $(40 \cdot 8$ \pm 1.9 vs $46.4 \pm 2.5 \mathrm{~mm}, P<0.0001)$. When the skeletal geometry results were corrected for this reduced tibial length (Table 1), there was a significant reduction in cortical thickness/tibial length ratio and periosteal circumference/ tibial length ratio at day 60 in the treated animals, whereas endosteal circumference to tibial length ratio showed a trend towards reduction. These skeletal changes resulted in a reduction in bone strength as reflected by lower stress-strain index in the treated animals.

At day 150 , previously treated animals had a significantly decreased endosteal circumference/tibial length ratio, leading to an increased cortical thickness/tibial length ratio in the treatment group. The smaller bones, however, still showed a reduced stress-strain index at day 150 .

Osteocalcin levels in treated animals were not significantly different from those measured in the control animals (letrozole $(n=17) 9 \cdot 352 \pm 0 \cdot 2841 \mathrm{ng} / \mathrm{ml}$ versus control $(n=19) \quad 8 \cdot 220 \pm 0.5438 \mathrm{ng} / \mathrm{ml}, P=0 \cdot 0835$; Fig. 1a), but letrozole-treated animals had lower RATLAPS levels $(47 \cdot 3$ \pm 8.6 vs $58 \cdot 1 \pm 7 \cdot 4 \mathrm{ng} / \mathrm{ml}, P=0 \cdot 0003$; Fig. $1 \mathrm{~b})$ than controls at the end of treatment.

\section{Growth}

The two groups had similar weight at the start of study. Treated animals had lower relative weight gain during treatment compared to controls $(179 \cdot 1 \pm 32 \cdot 3$ vs $354 \cdot 3$ $\pm 57 \cdot 8 \%, P<0 \cdot 0001)$ resulting in significantly lower weight than controls from day 10 onwards (Table 2 and Fig. 2a). This resulted in $37.5 \%$ lower weight in treated animals compared to controls at the end of treatment $(P<0 \cdot 0001$; Table 2$)$. Both

Table 2 Growth parameters observed in the study

\begin{tabular}{|c|c|c|c|}
\hline & $\begin{array}{c}\text { Treatment } \\
(n=22)\end{array}$ & $\begin{array}{l}\text { Control } \\
(n=23)\end{array}$ & $\boldsymbol{P}$ \\
\hline \multicolumn{4}{|l|}{ Category } \\
\hline \multicolumn{4}{|l|}{ Weight (g) } \\
\hline Day 0 & $101 \cdot 4 \pm 13 \cdot 5$ & $100 \cdot 2 \pm 9 \cdot 9$ & $0 \cdot 72$ \\
\hline Day 60 & $284 \cdot 2 \pm 27 \cdot 4$ & $455 \cdot 2 \pm 43 \cdot 8$ & $<0 \cdot 0001$ \\
\hline Day 150 & $391 \cdot 3 \pm 40 \cdot 0$ & $613 \cdot 3 \pm 80 \cdot 0$ & $<0 \cdot 0001$ \\
\hline \multicolumn{4}{|c|}{ Weight gain $\%$ of baseline } \\
\hline Day 1-60 & $179 \cdot 1 \pm 32 \cdot 3$ & $354 \cdot 3 \pm 57 \cdot 8$ & $<0 \cdot 0001$ \\
\hline Day $61-150$ & $37 \cdot 7 \pm 7 \cdot 2$ & $34 \cdot 7 \pm 7 \cdot 9$ & $0 \cdot 31$ \\
\hline \multicolumn{4}{|c|}{ Crown-rump length (cm) } \\
\hline Day 60 & $17 \cdot 5 \pm 0 \cdot 8$ & $19 \cdot 4 \pm 0 \cdot 7$ & $<0 \cdot 0001$ \\
\hline Day 150 & $18 \cdot 7 \pm 0 \cdot 5$ & $21 \cdot 1 \pm 0 \cdot 6$ & $<0 \cdot 0001$ \\
\hline \multicolumn{4}{|l|}{ Tibial length } \\
\hline Day 60 & $37 \cdot 2 \pm 2 \cdot 6(\mathrm{~mm})$ & $42 \cdot 0 \pm 1 \cdot 7(\mathrm{~mm})$ & $<0 \cdot 0001$ \\
\hline Day 150 & $40 \cdot 8 \pm 1 \cdot 9(\mathrm{~mm})$ & $46 \cdot 4 \pm 2 \cdot 5(\mathrm{~mm})$ & $<0.0001$ \\
\hline
\end{tabular}
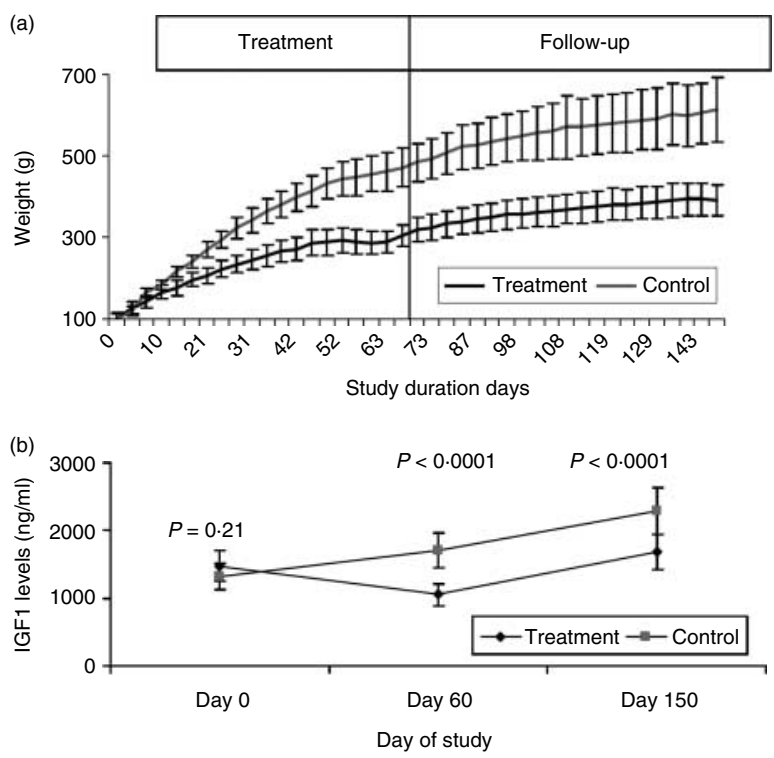

Figure 2 Effects of aromatase inhibitors on growth. (a) Treated animals had lower relative weight gain during treatment compared to controls $(179 \cdot 1 \pm 32 \cdot 3$ vs $354 \cdot 3 \pm 57 \cdot 8 \%, P<0 \cdot 0001)$ resulting in significantly lower weight than controls from day 10 onwards. The weight of treated animals was $37 \cdot 5 \%$ lower than controls. Both groups had similar relative weight gain $(37 \cdot 7 \pm 7 \cdot 2$ vs $34 \cdot 7 \pm 7 \cdot 9 \%$, $P=0 \cdot 31$ ) in the follow-up period; the weight of the treated animals, however, remained $36 \cdot 2 \%$ lower than controls at the end of study. (b) IGF1 levels were similar in the two groups at the start of study $(1475 \pm 95 \cdot 87$ vs $1316 \pm 63 \cdot 71 \mathrm{ng} / \mathrm{ml}, P=0 \cdot 21)$; levels were lower in the treated animals at the end of treatment $(1051 \cdot 6 \pm 268 \cdot 8 \mathrm{vs}$ $1706 \cdot 2 \pm 244 \cdot 2 \mathrm{ng} / \mathrm{ml}, P<0 \cdot 0001)$ and at the end of study (1682 \pm 40.53 vs $2282 \pm 53 \cdot 51 \mathrm{ng} / \mathrm{ml}, P<0 \cdot 0001)$.

groups had similar relative weight gain $(37 \cdot 7 \pm 7 \cdot 2$ vs $34 \cdot 7$ $\pm 7 \cdot 9 \%, P=0 \cdot 31)$ in the follow-up period; the weight of the treated animals, however, remained $36 \cdot 2 \%$ lower than controls at the end of study $(P<0 \cdot 0001)$. Linear growth was also compromised in the treatment group with lower crownrump length and tibial length at the end of treatment and at the end of study $(P<0 \cdot 0001$ for both). IGF1 levels were similar in the two groups at the start of study $(1475 \pm 95.87$ vs $1316 \pm 63.71 \mathrm{ng} / \mathrm{ml} ; P=0 \cdot 21$ ); levels were lower in the treated animals during treatment $(1051.6 \pm 268 \cdot 8$ vs $1706 \cdot 2 \pm 244 \cdot 2 \mathrm{ng} / \mathrm{ml}, P<0 \cdot 0001)$ and at the end of study $(1682 \pm 40 \cdot 53$ vs $2282 \pm 53 \cdot 51 \mathrm{ng} / \mathrm{ml}, P<0 \cdot 0001$; Fig. $2 \mathrm{~b})$. GH levels were unaffected by letrozole treatment $(21 \cdot 7 \pm 22.9$ vs $31 \cdot 8 \pm 22 \cdot 4 \mathrm{ng} / \mathrm{ml}, P=$ not significant).

\section{Prostate}

Letrozole-treated animals had larger anterior and dorsal lobes of prostate at the end of study when corrected for body weight (Table 3). No difference was noted in the weight of ventral and lateral prostate lobes corrected for body weight. Focal prostatic hyperplasia was observed in 15/19 treated animals $(78 \cdot 9 \%)$ with $4 \cdot 8 \pm 2 \cdot 6$ foci per tissue (Fig. 3a). None of the controls showed focal prostatic hyperplasia. A trend of 
Table 3 Organ weights of prostate and testis at the end of study (expressed as $\mathrm{g} / 100 \mathrm{~g}$ body weight)

\begin{tabular}{|c|c|c|c|}
\hline & $\begin{array}{l}\text { Treatment } \\
(n=22)\end{array}$ & $\begin{array}{l}\text { Control } \\
(n=23)\end{array}$ & $\boldsymbol{P}$ \\
\hline \multicolumn{4}{|l|}{ Parameter } \\
\hline $\begin{array}{l}\text { Ventral prostate } \\
(\mathrm{g} / 100 \mathrm{~g})\end{array}$ & $0 \cdot 099 \pm 0 \cdot 020$ & $0 \cdot 105 \pm 0 \cdot 021$ & $0 \cdot 28$ \\
\hline $\begin{array}{l}\text { Anterior prostate } \\
(\mathrm{g} / 100 \mathrm{~g})\end{array}$ & $0 \cdot 043 \pm 0 \cdot 009$ & $0 \cdot 035 \pm 0 \cdot 007$ & $0 \cdot 003$ \\
\hline $\begin{array}{l}\text { Lateral prostate } \\
\qquad(\mathrm{g} / 100 \mathrm{~g})\end{array}$ & $0 \cdot 036 \pm 0 \cdot 012$ & $0 \cdot 034 \pm 0 \cdot 009$ & $0 \cdot 57$ \\
\hline $\begin{array}{l}\text { Dorsal prostate } \\
(\mathrm{g} / 100 \mathrm{~g})\end{array}$ & $0 \cdot 060 \pm 0 \cdot 016$ & $0 \cdot 051 \pm 0 \cdot 012$ & $0 \cdot 08$ \\
\hline Testis (g/100 g) & $0 \cdot 877 \pm 0 \cdot 117$ & $0 \cdot 634 \pm 0 \cdot 113$ & $<0 \cdot 0001$ \\
\hline
\end{tabular}

increased percentage of PCNA-positive epithelial cells was observed in the treated group compared to controls $(4 \cdot 27$ $\pm 1 \cdot 28$ vs $2 \cdot 17 \pm 0 \cdot 43, P=0 \cdot 054$; Fig. $3 b)$.

\section{Reproductive measures}

Testicular size was increased in the treated animals at the end of study, as reflected by higher testicular weight corrected for body weight (Table 3). Letrozole treatment was associated with a reduction in LH levels. The two groups had similar levels at the start of treatment $(0 \cdot 28 \pm 0 \cdot 24$ vs $0 \cdot 36 \pm 0 \cdot 26 \mathrm{ng} / \mathrm{ml}$, $P=0 \cdot 318)$. LH levels were lower in the treatment group at day $60(0 \cdot 39 \pm 0 \cdot 33$ vs $0 \cdot 69 \pm 0 \cdot 27 \mathrm{ng} / \mathrm{ml}, P<0 \cdot 0001)$ and were similar by the end of study $(0.98 \pm 0.32$ vs $1.1 \pm 0.57 \mathrm{ng} / \mathrm{ml}$,

(a)

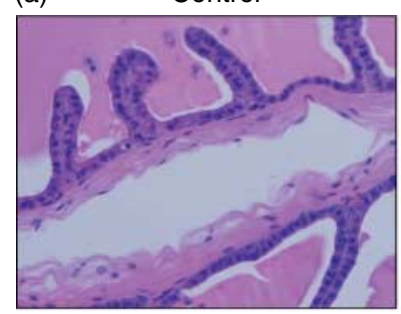

Letrozole

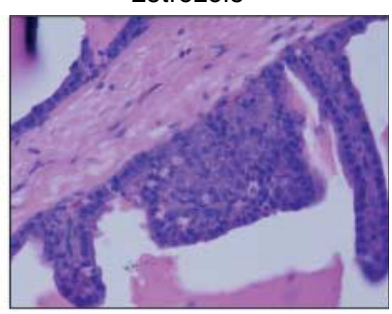

(b)

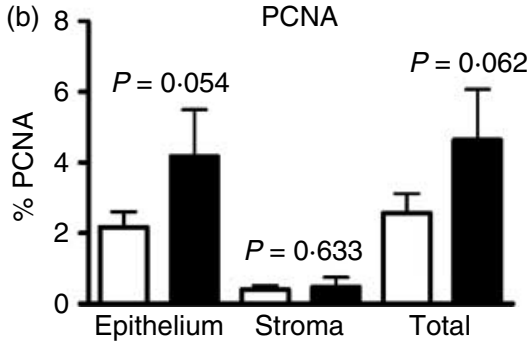

Figure 3 Effects of letrozole treatment on prostate. (a) Focal prostatic hyperplasia was observed in 15/19 treated animals $(78.9 \%)$ with $4 \cdot 8 \pm 2 \cdot 6$ foci per tissue. None of the controls showed focal prostatic hyperplasia. (b) Letrozole-treated animals showed a trend of increased percentage of PCNA-positive epithelial cells compared to controls $(4 \cdot 27 \pm 1 \cdot 28$ vs $2 \cdot 17 \pm 0 \cdot 43, P=0 \cdot 054)$. Solid bars represent letrozole-treated animals and open bars represent controls (mean \pm S.D).
$P=0 \cdot 409)$. No differences were observed in the FSH $(7 \cdot 16 \pm 1.99$ vs $8 \cdot 13 \pm 1.98 \mathrm{ng} / \mathrm{ml}, P=0.117)$ and testosterone levels $(2 \cdot 06 \pm 1 \cdot 13 \mathrm{vs} 1 \cdot 82 \pm 1 \cdot 13 \mathrm{ng} / \mathrm{ml}, P=0 \cdot 482)$ at the end of treatment in the two groups.

\section{Body composition and metabolic parameters}

Letrozole treatment did not affect the proportion of fat mass at the end of treatment $(20 \cdot 2 \pm 4 \cdot 8$ vs $19 \cdot 4 \pm 4 \cdot 7 \%, P=0 \cdot 58)$. Treated animals, however, had a lower proportion of body fat at the end of study $(23 \cdot 5 \pm 5 \cdot 8$ vs $30 \cdot 1 \pm 7 \cdot 0 \%, P<0 \cdot 0001)$. The insulin to glucose ratio was similar in the two groups during treatment $(0 \cdot 37 \pm 0 \cdot 15$ vs $0 \cdot 43 \pm 0 \cdot 26, P=0 \cdot 38)$.

\section{Discussion}

Our study has demonstrated significant long-term adverse effects of aromatase inhibition in peripubertal male rats. Peripubertal aromatase inhibition led to reduction in bone strength, impaired growth and prostatic hyperplasia. Importantly, these effects were long standing and persisted in adulthood.

The demonstration of persistent compromise in bone strength in the letrozole-treated animals was a critical finding in our study. This reiterates the observations of reduced bone strength in aromatase-deficient men (Bilezikian et al. 1998), aromatase knockout mice (Oz et al. 2000) and older male Wistar rats treated with aromatase inhibitor vorozole (Vanderschueren et al. 1997). In the first two models, however, aromatase inhibition was lifelong, whereas in the last model, aromatase inhibition only occurred in adulthood. In contrast, in our model, aromatase inhibition was limited to the peripubertal period, similar to its current usage in short boys. Abnormalities in skeletal geometry (reduced periosteal and endosteal circumference, bone length and cortical thickness), with resultant smaller, thinner bones, even when corrected for tibial length, were seen in letrozole-treated animals. However, bone mineral density was preserved. This suggests a direct inhibitory effect of the drug on periosteal apposition over and above the changes observed in linear growth. Treated animals showed catchup in bone size and periosteal apposition after discontinuation of treatment resulting in similar bone size corrected for tibial length in the two groups at last follow-up. The reduced stress-strain index observed at the end of study thus pertains to the small overall size of the bone. However, this smaller bone is still at increased risk of fracture compared to the larger bones observed in the control animals.

The change in bone geometry, but not density, indicates a differential role of oestrogen in the male skeleton with predominant effect on skeletal growth and cortical modelling and relatively minor effect on bone mass accrual. This is in concordance with the observations on growing wild-type and androgen receptor knockout male mice (Venken et al. 2006). The lack of variation in osteocalcin results and reduced bone 
resorption reflected by the RATLAPS assay between treated and untreated animals at this dose are consistent with the only published data in rats (Kumru et al. 2007). Given that osteocalcin reflects only one aspect of osteoblast function, it is possible that effects are being mediated on bone formation, which are not seen in the osteocalcin results.

Our findings highlight the limitations of the currently available evidence regarding bone safety in aromatase inhibitor-treated boys. These studies have assumed a lack of adverse skeletal effects by the demonstration of similar DXAmeasured areal bone mineral density (BMD) and bone markers compared to controls, and have not used PQCT scans. Importantly, DXA does not provide robust information about skeletal geometry, the main site of oestrogen action. In three out of four of these studies, testosterone or $\mathrm{GH}$, agents with direct anabolic effects on bone, was used in addition to aromatase inhibitors. Although aromatase inhibitors may be combined with $\mathrm{GH}$ and testosterone in boys with $\mathrm{GH}$ deficiency and constitutional delay of puberty and growth respectively, they are frequently used as a stand-alone treatment in idiopathic short stature, the most common indication in clinical practice. The observations of studies with combination treatment cannot be extrapolated to boys with idiopathic short stature. Another important factor in these studies is the relatively short follow-up duration (1-3 years). With fragility fracture the most important long-term indicator of bone health, the finding of vertebral compression in aromatase inhibitor-treated boys within 10 years of the initial treatment is particularly important (Dunkel 2009, Hero et al. 2009) and that this occurred despite normal DXA-measured areal BMD suggests that areal BMD is not an adequate predictor of bone strength in this setting.

A second significant observation of our study was the growth suppression induced by letrozole, with treated animals weighing $37 \cdot 5 \%$ less than controls. This is similar to the observation of Vandescheuren et al. (1997) showing 16\% lower weight in vorozole-treated growing Wistar rats, and Turner et al. (2000) showing 24\% lower weight in anastrazoletreated adult male rats. Intriguingly, Eshet et al. (2004) observed increased weight gain in male mice treated with letrozole for 10 days. This is consistent with reports in female letrozole-treated rats, which showed weight gain and changes consistent with polycystic ovarian syndrome (Manneras et al. 2007). Our study examining male rats only is not able to shed further light on the discrepancy between reports in different genders. Importantly, impairment in weight gain in males was evident only after 2 weeks of treatment in our and other studies, as distinct from females. Longer duration of treatment is thus expected to result in growth inhibition as observed in our study. This could represent effects of oestrogen deficiency or toxic effects of the drug. However, no toxic effects were observed during the study, with the only deaths being due to anaesthetic complications. Although food intake was not formally quantified, feeding behaviour and activity were similar in treated and control animals, arguing against a toxic effect of the drug. The growth-suppressing effect of aromatase inhibition may be due to inhibition of IGF1 production due to effects of oestrogen deficiency on $\mathrm{GH}$ receptor expression or signalling, or loss of GH-independent hepatic production of IGF1 (Venken et al. 2005). Although this impaired weight gain may partially explain the observed skeletal phenotype, it would seem that even in the female model where there is weight gain, the amount of bone formation as measured by bone mineral content per weight is reduced, suggesting a direct effect of letrozole in impaired bone mass accrual in both genders (Manneras et al. 2007).

The third important finding of our study was the demonstration of focal prostatic hyperplasia along with increased size of the anterior and dorsal prostate lobes (when corrected for body weight) in letrozole-treated animals. As for the other novel findings, these changes were apparent well beyond the treatment period to at least the equivalent of human age of 30 years. The balance of androgens and oestrogen is critical in both prostate physiology and pathologies (Harkonen \& Makela 2004, Prins et al. 2006, McPherson et al. 2008). Perturbation leading to hormonal imbalance in early neonatal life or on aging causes prostatic pathologies (Prins et al. 2007). The demonstration of prostatic hyperplasia due to short-term aromatase inhibition in peripubertal animals is entirely consistent with the observation that long-term oestrogen deficiency causes prostatic hyperplasia and hypertrophy in adult aromatase knockout (ArKO) mice (McPherson et al. 2001). These observations indicate the need for long-term follow-up for evaluation of prostatic health in young boys treated with aromatase inhibitors.

Adverse testicular effects are an important area of concern in the use of aromatase inhibitors in boys in view of impaired spermatogenesis in adult male ArKO mice (Robertson et al. 1999) and one man with aromatase deficiency (Carani et al. 1997). Although the testicular size of treated animals was increased when corrected for body weight, no obvious abnormality in testicular histology was observed in our study. Treatment with anastrazole for up to 1 year in adult male Wistar rats, however, resulted in the development of Sertoli cells-only testis in $10 \%$ of animals, with varying degrees of germ cell loss in 1-2\% of seminiferous tubules (Turner et al. 2000). These findings suggest that severe adverse testicular effects of aromatase deficiency may manifest only after prolonged oestrogen deficiency, as seen in male ArKO mice, which are initially fertile, and impaired spermatogenesis occurs as a late event (Robertson et al. 1999).

The tissue effects of aromatase inhibitors in males are largely related to local oestrogen deficiency, as locally produced oestrogen plays a much more important role compared with circulating oestradiol $\left(\mathrm{E}_{2}\right)$ in males. Tissue $\mathrm{E}_{2}$ levels are therefore more relevant than circulating $\mathrm{E}_{2}$ levels. Studies on aromatase inhibition have failed to detect a difference in circulating $\mathrm{E}_{2}$ levels despite evident effect on the hypothalamic-pituitary axis (Turner et al. 2000). $\mathrm{E}_{2}$ levels were undetectable by the methods used in the study. Testosterone levels were not elevated in the treated animals at the end of treatment. This may be related to the fact that testosterone 
levels were measured after 60 days of treatment. Importantly, Turner et al. in a study of effects of anastrazole in older male Wistar rats observed that although testosterone levels were higher in treated animals initially, no significant difference was observed between groups for either testosterone or FSH levels after prolonged treatment. Similarly, we were unable to demonstrate pituitary effects from assessment of FSH levels as the samples were taken only after cessation of treatment.

In contrast to observations in aromatase knockout mice (Jones et al. 2000) and aromatase-deficient men (Morishima et al. 1995) who develop an adiposity phenotype and insulin resistance, no effect of aromatase inhibition on body composition and insulin levels was observed at the end of treatment.

In summary, our study has demonstrated adverse effects of aromatase inhibition on skeleton, growth and prostate in peripubertal male rats. Although caution needs to be exercised in extrapolating these findings into the clinic due to the longer duration of aromatase inhibitor treatment in our animal model and possible species differences in drug response, the findings nevertheless point to serious potential long-term adverse effects of such therapy in peripubertal short boys. Further characterisation of long-term adverse effects of aromatase inhibitors in animal models of peripubertal males is thus highly desirable before further widespread use in young boys. Our findings also point to the need for developing selective oestrogen inhibition strategies such that oestrogen action on growth plate is inhibited, while beneficial effects in other tissues are preserved.

\section{Declaration of interest}

The authors declare that there is no conflict of interest that could be perceived as prejudicing the impartiality of the research reported.

\section{Funding}

The study was supported by an unrestricted investigator initiated research grant from Pfizer Australia to GAW (AUS-NDE-07-002) and funding from the National Health and Medical Research Concil (545931).

\section{Author contribution statement}

The study was conducted in the laboratories of GAW, JDW and GPR. AB conceived the study. AB, GAW, VCR, JDW and GPR were involved in the planning and implementation of the study. PJS, SJM and WJA contributed to the conduct of the study. $\mathrm{AB}$ collected data, performed the data analysis and drafted the manuscript. All the authors reviewed and contributed to the final version of the manuscript.

\section{Acknowledgements}

The authors acknowledge the significant role of Mr Magdy Sourial, Officer, Animal Research Laboratory, Royal Children's Hospital, Melbourne, Victoria, Australia and Mrs Sue Kantor, Department of Medicine, University of Melbourne, Melbourne, Victoria, Australia, in the conduct of the study.

\section{References}

Bilezikian JP, Morishima A, Bell J \& Grumbach MM 1998 Increased bone mass as a result of estrogen therapy in a man with aromatase deficiency. New England Journal of Medicine 339 599-603. (doi:10.1056/ NEJM199808273390905)

Carani C, Qin K, Simoni M, Faustini-Fustini M, Serpente S, Boyd J, Korach KS \& Simpson ER 1997 Effect of testosterone and estradiol in a man with aromatase deficiency. New England Journal of Medicine 337 91-95. (doi:10.1056/NEJM199707103370204)

Dunkel L 2009 Update on the role of aromatase inhibitors in growth disorders. Hormone Research 71 (Supplement 1) 57-63. (doi:10.1159/ 000178040)

Eshet R, Maor G, Ben Ari T, Ben Eliezer M, Gat-Yablonski G \& Phillip M 2004 The aromatase inhibitor letrozole increases epiphyseal growth plate height and tibial length in peripubertal male mice. Journal of Endocrinology 182 165-172. (doi:10.1677/joe.0.1820165)

Harkonen P \& Makela S 2004 Role of estrogens in development of prostate cancer. Journal of Steroid Biochemistry and Molecular Biology 92 297-305. (doi:10.1016/j.jsbmb.2004.10.016)

Hero M, Norjavaara E \& Dunkel L 2005 Inhibition of estrogen biosynthesis with a potent aromatase inhibitor increases predicted adult height in boys with idiopathic short stature: a randomized controlled trial. Journal of Clinical Endocrinology and Metabolism 90 6396-6402. (doi:10.1210/ jc.2005-1392)

Hero M, Ankarberg-Lindgren C, Taskinen MR \& Dunkel L 2006a Blockade of oestrogen biosynthesis in peripubertal boys: effects on lipid metabolism, insulin sensitivity, and body composition. European Journal of Endocrinology 155 453-460. (doi:10.1530/eje.1.02226)

Hero M, Wickman S \& Dunkel L $2006 b$ Treatment with the aromatase inhibitor letrozole during adolescence increases near-final height in boys with constitutional delay of puberty. Clinical Endocrinology 64 510-513. (doi:10.1111/j.1365-2265.2006.02499.x)

Hero M, Makitie O, Kroger H, Nousiainen E, Toiviainen-Salo S \& Dunkel L 2009 Impact of aromatase inhibitor therapy on bone turnover, cortical bone growth and vertebral morphology in pre- and peripubertal boys with idiopathic short stature. Hormone Research 71 290-297. (doi:10.1159/ 000208803)

Jones ME, Thorburn AW, Britt KL, Hewitt KN, Wreford NG, Proietto J, Oz OK, Leury BJ, Robertson KM, Yao S et al. 2000 Aromatase-deficient (ArKO) mice have a phenotype of increased adiposity. PNAS 97 12735-12740. (doi:10.1073/pnas.97.23.12735)

Kumru S, Yildiz AA, Yilmaz B, Sandal S \& Gurates B 2007 Effects of aromatase inhibitors letrozole and anastrazole on bone metabolism and steroid hormone levels in intact female rats. Gynecological Endocrinology 23 556-561. (doi:10.1080/09513590701557119)

Manneras L, Cajander S, Holmang A, Seleskovic Z, Lystig T, Lonn M \& Stener-Victorin E 2007 A new rat model exhibiting both ovarian and metabolic characteristics of polycystic ovarian syndrome. Endocrinology 148 3781-3791. (doi:10.1210/en.2007-0168)

Mauras N, Welch S, Rini A \& Klein KO 2004 An open label 12-month pilot trial on the effects of the aromatase inhibitor anastrozole in growth hormone (GH)-treated GH deficient adolescent boys. Journal of Pediatric Endocrinology and Metabolism 17 1597-1606.

Mauras N, Bell J, Snow BG \& Winslow KL 2005 Sperm analysis in growth hormone-deficient adolescents previously treated with an aromatase inhibitor: comparison with normal controls. Fertility and Sterility $\mathbf{8 4}$ 239-242. (doi:10.1016/j.fertnstert.2005.02.012)

Mauras N, Gonzalez de Pijem L, Hsiang HY, Desrosiers P, Rapaport R, Schwartz ID, Klein KO, Singh RJ, Miyamoto A \& Bishop K 2008 Anastrozole increases predicted adult height of short adolescent males treated with growth hormone: a randomized, placebo-controlled, multicenter trial for one to three years. Journal of Clinical Endocrinology and Metabolism 93 823-831. (doi:10.1210/jc.2007-1559)

McPherson SJ, Wang H, Jones ME, Pedersen J, Iismaa TP, Wreford N, Simpson ER \& Risbridger GP 2001 Elevated androgens and prolactin in 
aromatase-deficient mice cause enlargement, but not malignancy, of the prostate gland. Endocrinology 142 2458-2467. (doi:10.1210/ en.142.6.2458)

McPherson SJ, Ellem SJ \& Risbridger GP 2008 Estrogen-regulated development and differentiation of the prostate. Differentiation 76 660-670. (doi:10.1111/j.1432-0436.2008.00291.x)

Morishima A, Grumbach MM, Simpson ER, Fisher C \& Qin K 1995 Aromatase deficiency in male and female siblings caused by a novel mutation and the physiological role of estrogens. Journal of Clinical Endocrinology and Metabolism 80 3689-3698. (doi:10.1210/jc.80.12.3689)

Murata Y, Robertson KM, Jones ME \& Simpson ER 2002 Effect of estrogen deficiency in the male: the ArKO mouse model. Molecular and Cellular Endocrinology 193 7-12. (doi:10.1016/S0303-7207(02)00090-4)

Nolan LA \& Levy A 2006 The effects of testosterone and oestrogen on gonadectomised and intact male rat anterior pituitary mitotic and apoptotic activity. Journal of Endocrinology 188 387-396. (doi:10.1677/ joe.1.06508)

O’Donnell L, McLachlan RI, Wreford NG \& Robertson DM 1994 Testosterone promotes the conversion of round spermatids between stages VII and VIII of the rat spermatogenic cycle. Endocrinology 135 2608-2614. (doi:10.1210/en.135.6.2608)

Oz OK, Zerwekh JE, Fisher C, Graves K, Nanu L, Millsaps R \& Simpson ER 2000 Bone has a sexually dimorphic response to aromatase deficiency. Journal of Bone and Mineral Research 15 507-514. (doi:10.1359/jbmr.2000. 15.3.507)

Prins GS, Huang L, Birch L \& Pu Y 2006 The role of estrogens in normal and abnormal development of the prostate gland. Annals of the New York Academy of Sciences 1089 1-13. (doi:10.1196/annals.1386.009)

Prins GS, Birch L, Tang WY \& Ho SM 2007 Developmental estrogen exposures predispose to prostate carcinogenesis with aging. Reproductive Toxicology 23 374-382. (doi:10.1016/j.reprotox.2006.10.001)

Robertson KM, O'Donnell L, Jones ME, Meachem SJ, Boon WC, Fisher CR, Graves KH, McLachlan RI \& Simpson ER 1999 Impairment of spermatogenesis in mice lacking a functional aromatase (cyp 19) gene. PNAS 96 7986-7991. (doi:10.1073/pnas.96.14.7986)

Shulman DI, Francis GL, Palmert MR \& Eugster EA 2008 Use of aromatase inhibitors in children and adolescents with disorders of growth and adolescent development. Pediatrics 121 e975-e983. (doi:10.1542/peds. 2007-2081)

Smith EP, Boyd J, Frank GR, Takahashi H, Cohen RM, Specker B, Williams TC, Lubahn DB \& Korach KS 1994 Estrogen resistance caused by a mutation in the estrogen-receptor gene in a man. New England Journal of Medicine 331 1056-1061. (doi:10.1056/NEJM19941020 3311604)

Takeda K, Toda K, Saibara T, Nakagawa M, Saika K, Onishi T, Sugiura T \& Shizuta Y 2003 Progressive development of insulin resistance phenotype in male mice with complete aromatase (CYP19) deficiency. Journal of Endocrinology 176 237-246. (doi:10.1677/joe.0.1760237)

Turner KJ, Morley M, Atanassova N, Swanston ID \& Sharpe RM 2000 Effect of chronic administration of an aromatase inhibitor to adult male rats on pituitary and testicular function and fertility. Journal of Endocrinology 164 225-238. (doi:10.1677/joe.0.1640225)

Vanderschueren D, van Herck E, Nijs J, Ederveen AG, De Coster R \& Bouillon R 1997 Aromatase inhibition impairs skeletal modeling and decreases bone mineral density in growing male rats. Endocrinology 138 2301-2307. (doi:10.1210/en.138.6.2301)

Venken K, Schuit F, Van Lommel L, Tsukamoto K, Kopchick JJ, Coschigano K, Ohlsson C, Moverare S, Boonen S, Bouillon R et al. 2005 Growth without growth hormone receptor: estradiol is a major growth hormone-independent regulator of hepatic IGF-I synthesis. Journal of Bone and Mineral Research 20 2138-2149. (doi:10.1359/JBMR.050811)

Venken K, De Gendt K, Boonen S, Ophoff J, Bouillon R, Swinnen JV, Verhoeven G \& Vanderschueren D 2006 Relative impact of androgen and estrogen receptor activation in the effects of androgens on trabecular and cortical bone in growing male mice: a study in the androgen receptor knockout mouse model. Journal of Bone and Mineral Research 21 576-585. (doi:10.1359/jbmr.060103)

Wickman S, Sipila I, Ankarberg-Lindgren C, Norjavaara E \& Dunkel L 2001 A specific aromatase inhibitor and potential increase in adult height in boys with delayed puberty: a randomised controlled trial. Lancet 357 1743-1748. (doi:10.1016/S0140-6736(00)04895-9)

Wickman S, Kajantie E \& Dunkel L 2003 Effects of suppression of estrogen action by the $\mathrm{p} 450$ aromatase inhibitor letrozole on bone mineral density and bone turnover in pubertal boys. Journal of Clinical Endocrinology and Metabolism 88 3785-3793. (doi:10.1210/jc.2002-021643)

\section{Received in final form 1 July 2010 \\ Accepted 23 July 2010 \\ Made available online as an Accepted Preprint 30 July 2010}

